\title{
From the Editors: Readers Talk Back
}

In an earlier CQ editorial (Vol. 19, No. 1, January 2010,) we offered some suggested "Do's and Don'ts" for authors submitting papers to bioethics journals and we invited readers' comments, including their own experiences. Responses from readers were prompt, numerous, and sometimes battle scarred. They fell into two categories: (1) advice intended for fellow authors and (2) comments directed at editors regarding the review process. Examples of suggestions for fellow authors included: "When you send a paper to a journal, already have your cover letter prepared for your next choice so if a rejection comes your disappointment won't feel like such a setback." and "Before submitting a paper, always have it critiqued by colleagues you trust to tell you the truth not just what you want to hear-and more than one if possible." and "Carefully check your submission correspondence. I once sent a paper to a journal erroneously addressed to a rival publication in the cover letter-I never heard anything back."

Second, in addition to advice for authors, many readers directed their responses to editors and the review process. They took the opportunity to provide their own comments-often frustrated-as to better ways in which editors could discharge their responsibilities to authors. The most heated of these correspondences echoed the views of T.S. Eliot, who referred to editors as "pompous avuncular brutes," and Kingsley Amis's description of an editor as someone who "prowls through our copy like an overzealous gardener with a pruning hook, on the watch for any phrase he senses you were rather pleased with, preferably one that also clinches your argument and if possible is essential to the general drift of the surrounding passage." (as quoted by Giles Harvey in The New York Review of Books, May 27, 2010, p. 38).

If we are to be honest with ourselves, the letters we received from readers provide a rich opportunity to look in our own editorial mirrors and try not to flinch from the reflection.

Here are selected comments from readers. When mentioned, the names of specific journals have been omitted. In general, the areas most frequently criticized are as follows.

\section{Length of Time for Review}

The journal had my paper under review for 2 years before I withdrew it.

I hate to bother editors by asking what is happening with my paper but when I don't hear for so long I feel I've been forgotten; why can't they keep me informed?

How long should a review take? Adding the time it takes for a review to the length of time between acceptance and publication, a piece that was once timely has lost its edge. 
An editor criticized my paper because he said the data were stale. I wanted to say "But they weren't when I sent you the paper"-but I didn't.

\section{Reviews and Rejections}

The reviewers missed my point and did not recommend publication; the editors backed them up but when I submitted to another journal the paper was accepted right away without changes.

It was years ago but I still remember that after a long wait from a prestigious journal, when the rejection finally came, the sting was compounded by the fact that the letter had coffee stains all over it. The message to me was that I didn't even rate a fresh piece of paper.

Two reviewers sent diametrically opposed responses to my paper and the editor decided to go with the negative review rather than the positive one and did not look further. With such disparity unchallenged, I chose not to submit to that journal again.

I am puzzled by situations in which I submit a paper that I deem to be unworthy but the editors publish it anyway, as well as other times when I deem a paper unworthy, the editors reject it, but I find it a year later in another journal (of supposedly equal stature).

An editor invited me to revise and resubmit my paper in response to a reviewer's comments. I made extensive revisions and sent the revised paper with an explanation of my revisions and responses. The editor later sent me the reviewer's reply to my revised paper but now there was a whole new set of objections, none of which had been presented in the original review. I complained but nothing was done and I withdrew the paper.

I believe that friendship is too often a factor in editorial decisions. Since becoming associated with a number of journals in an editorial capacity, none of the papers I've submitted to those journals has been rejected. That cannot be right, can it? I am not complaining about these journals, of course, but what about the others that will only publish papers by THEIR friends and reject MY contributions?

A reviewer from a prestigious university said that my colleague's submission was "for Dummies." First, should a professional make such a gratuitous remark and secondly, should the editor have passed such an unhelpful remark on to the author?

\section{Length of Time before Publication}

When I phoned the editor and asked why my paper had not appeared in the year he said it would be, his reply was, "What year is it?"

I actually had an editor tell me he had forgotten about my paper and that there was such a backlog of accepted papers in the queue it would be several more years before publication.

We can speak only for one journal, but the issues pointed out by readers are ones we struggle with every day. We do know how important it is for authors to have a timely review, and a goal we set for ourselves is that we try diligently to have 
reviewers' comments back to authors within six weeks. Circumstances arise that sometimes make us fall short, but we remain steadfast in our aim. Frequently, papers are submitted to $C Q$ that, because of topic or readership, we deem would be a better fit for another journal, and we advise authors when we think this to be the case. As for the role of reviewers at $C Q$, we rely on our trusted panel to provide knowledgeable and objective analysis. Reviewers are selected for specific papers based on their areas of expertise, experience in reviewing, and dependability in providing a timely review. It would be highly unusual for us to second-guess recommendations from a reviewer unless we felt there were good reasons. To date, our reviewers have been in general agreement in their evaluations. The reality of a quarterly journal is that we have space limitations to consider and we decline papers that we do not think we can publish in a timely manner. It is important to us that our authors feel they and their work have been well served.

We hear you. 